\title{
Long-term Results after Laparoscopic Resection for Colorectal Cancer within a Fast-track Regimen in the Elderly: A Prospective Study
}

\author{
Orhan Bulut $^{1}$ and Per Jess*,2,3 \\ ${ }^{1}$ Department of Colorectal Surgery, Hillerød Hospital, Denmark; ${ }^{2}$ Department of Surgery, Roskilde Hospital, Denmark; \\ ${ }^{3}$ Institute of Surgery and Internal Medicine, University of Copenhagen, Denmark
}

\begin{abstract}
Introduction: Trials of laparoscopic surgery for colorectal cancer in elderly with co-morbidity are needed. The aim of the present study was to evaluate the oncologic outcome after laparoscopic resection for non-metastatic colorectal cancer within a fast-track regimen comparing patients $\geq 75$ years of age to patients $<75$ years of age.

Methods: A total of 55 patients were laparoscopically operated upon for non-metastatic colorectal cancer in February 2001- March 2003. Twenty-nine patients were $\geq 75$ years old and 26 were younger. All patients had a perioperative fasttrack regimen. They were followed up for median 60 months.

Results: The two age groups were comparable with regard to sex distribution, operative procedures and cancer stage. The co-morbidity (ASA score) was higher in the elderly group $(\mathrm{p}=0.05)$ as well as the perioperative complication rate, $24 v s$. $15 \%(\mathrm{p}=0.3)$. The five-year overall survival was $66 \%$ in the elderly group $v s .69 \%$ in the younger group ( $\mathrm{p}=0.9)$. The disease-free survival was 62 vs. $69 \%$, respectively $(\mathrm{p}=0.1)$. The recurrence rate was 7 vs. $19 \%$, respectively $(\mathrm{p}=0.2)$. For all the patients together the recurrence rate was $13 \%$ with no significant differences between the stage groups $(\mathrm{p}=0.4)$.

Conclusion: Laparoscopic surgery and fast-track regimen together seem to have a beneficial effect on long-term oncologic outcome in the elderly.
\end{abstract}

Keywords: Laparoscopy, fast-track surgery, colorectal cancer, elderly.

\section{INTRODUCTION}

The beneficial short-term effect of laparoscopic colorectal cancer surgery in elderly people with regard to reductions in length of hospital stay, morbidity and mortality rates is shown in several studies [1-4]. A recent Cochrane analysis of long-term results of laparoscopic colorectal cancer resection concluded that laparoscopic surgery for colon cancer is a safe procedure with a survival rate equal to survival after open surgery, but trials that also include elderly patients with co-morbidity are needed [5]. In a multivariate analysis of potential risk factors for intra- and postoperative complications in 1316 elective laparoscopic colorectal procedures it was shown that age $\geq 75$ years was a significant risk for intraand postoperative complications [6]. It has also been shown that the presence of postoperative complications not only affects the short-term results of resection of colorectal cancer, but the long-term oncologic outcomes are also adversely affected in open surgery [7]. Thus, in spite of laparoscopic colorectal surgery has a beneficial short term effect with regard to complications compared to open surgery, the complication rate is supposed to increase in older age because of co-morbidity and for that reason a poorer oncologic result could be expected in cancer surgery. However, in a single study of laparoscopic resection for colorectal cancer in 101 selected octogenarians the long-term oncologic outcomes seemed favourable [8]. Furthermore, laparoscopic surgery

*Address correspondence to this author at the Department of Surgery, Roskilde Hospital, DK-4000 Roskilde, Denmark; Tel: +0045 47323095; Fax: +0045 47323009; E-mail: pjss@ @egionsjaelland.dk combined with a fast-track regimen may further improve the postoperative course for the patients by further reducing the postoperative complications and decreasing the length of stay in hospital without compromising the surgical outcome [9].

The aim of the present study was to evaluate the oncologic long-term results after laparoscopic resection for non-metastatic colon cancer within a fast-track regimen in an unselected cohort of patients comparing the patients $\geq 75$ years of age to patients $<75$ years of age.

\section{METHODS}

In the period from February 2001 to March 2003, 55 patients were laparoscopically operated upon for nonmetastatic colon cancer at Department of Colorectal Surgery, Hillerød Hospital. All the operations were performed by the same surgeon. Operative procedures, adjuvant treatment as well as short-term results of the operations have been published earlier [10]. All patients had a perioperative fast-track regimen as first suggested by Kehlet and co-workers [11]. Our setup was the same as described by Hammer et al. in their recent article about implementation of such a regimen into daily practice [12]. The regimen contained: no preoperative bowel cleansing, no drains nor tubes, mobilization and normal meal the evening on the day of surgery, epidural analgesia, oral laxatives, and a planned discharge on postoperative day 3 .

The characteristics of the patients with regard to age, sex, ASA (American Society of Anesthesiologists) score, operative procedure and stage (according to TNM classification), 
Table 1. Characteristics of Patients with Non-Metastatic Colon Cancer with Regard to Sex, Age, American Society of Anesthesiologists (ASA) Score, Operative Procedure, Stage (According to TNM Classification), Intra- and Postoperative Complications and Postoperative Hospital Stay in Patients $\geq 75$ Years and $<75$ Years, respectively

\begin{tabular}{|c|c|c|c|}
\hline & Patients $\geq 75$ years $(\mathrm{N}=29)$ & Patients $<75$ years $(\mathrm{N}=26)$ & $P$ value \\
\hline \multicolumn{4}{|l|}{ Age (yr) } \\
\hline \multicolumn{4}{|l|}{ Sex* } \\
\hline (female/male) & $17 / 12(59 / 41)$ & $15 / 11(58 / 42)$ & 0.95 \\
\hline Score 1 & $0(0)$ & $2(8)$ & \\
\hline Score 2 & $15(52)$ & $17(65)$ & \\
\hline Score 3 & $14(48)$ & $7(27)$ & \\
\hline Operative procedure* & & & 0.91 \\
\hline Sigmoid colectomy & $6(21)$ & $6(23)$ & \\
\hline Rectosigmoid resection & $6(21)$ & $7(27)$ & \\
\hline Stage* & & & 0.31 \\
\hline I & $6(21)$ & $5(19)$ & \\
\hline II & $16(55)$ & $10(39)$ & \\
\hline III & $7(24)$ & $11(42)$ & \\
\hline Intra- and postoperative Complications* & $7(24)$ & $4(15)$ & 0.32 \\
\hline Postoperative hospital stay (days)(median, range) & $5(2-10)$ & $5(2-30)$ & 0.20 \\
\hline
\end{tabular}

*Numbers in brackets are percentages.

intra- and postoperative complications and postoperative hospital stay in the two age groups $(\geq 75$ years and $<75$ years, respectively) are shown in Table 1. All patients were followed up according to a pre-established protocol which included medical history, physical examination and laboratory studies including serum carcinoembryonic antigen (CEA) levels 1 and 3 months after surgery and hereafter once a year, where abdominal ultrasonography and chest $\mathrm{x}$ ray or computed tomography of chest and abdomen were performed, as well. The median follow-up was 60 months (range, 6-78).

\section{Statistical Analyses}

Non-parametric statistics were used, inclusive $\chi^{2}$-test, Mann-Whitney test, Kaplan-Meier analysis and log rank test. Statistical significance was set at $P<0.05$.

\section{RESULTS}

\section{Patient Characteristics}

There were no significant differences between the two age groups of patients with regard to sex distribution, operative procedures or stage (Table 1). Not surprisingly, a tendency was found in the elderly group towards a higher ASA score $(\mathrm{p}=0.05)$. The perioperative complication rate was also higher in the elderly group (24\% versus $15 \%)$, but the differ- ence was not statistically different $(\mathrm{p}=0.32)$ (Table 1). The 30 -day mortality was $2 \%$ ( 1 patient in the group $<75$ years).

\section{Survival}

Five-year oncologic outcomes with regard to overall survival, disease-free survival and recurrence in the two groups are shown in Table 2 . The overall survival was nearly similar: $66 \%$ in the elderly group and $69 \%$ in the younger group $(\mathrm{p}=0.9)$ (Fig. 1). The disease-free survival was $62 \%$ and $69 \%$, respectively $(\mathrm{p}=0.1)$. For all the patients the overall survival was $69 \%$ and the disease-free survival $67 \%$. The recurrence rate for the elderly patients was $7 \%$ versus $19 \%$ in the younger group, but the difference was not significant. The recurrence rates for all patients together with regard to the different stage groups were $0 \%$ for stage I, $15 \%$ for stage II and $17 \%$ for stage III. The differences were not significant $(\mathrm{p}=0.4)$. The recurrence rate for all the patients together was $13 \%$.

\section{DISCUSSION AND CONCLUSION}

A meta-analysis of four randomized studies (Barcelona, COST, COLOR and CLASICC) with 1536 patients left for analysis showed that laparoscopically assisted colectomy for cancer was oncologically safe compared to the open approach [13]. This was confirmed in a recent Cochrane review 
Table 2. Tumor Recurrence and Survival

\begin{tabular}{|c|c|c|c|}
\hline & Patients $>75$ years $(\mathrm{N}=29)$ & Patients $<75$ years $(N=26)$ & $P$ value \\
\hline Overall survival (\%) & $19(66 \%)$ & $18(69 \%)$ & 0.9 \\
\hline \multicolumn{4}{|l|}{ Causes of death } \\
\hline Perioperative mortality & $1(3 \%)$ & $0(0 \%)$ & 0.9 \\
\hline Others & $8(28 \%)$ & $3(12 \%)$ & 0.1 \\
\hline Tumor recurrence (\%) & $2(7 \%)$ & $5(19 \%)$ & 0.2 \\
\hline
\end{tabular}

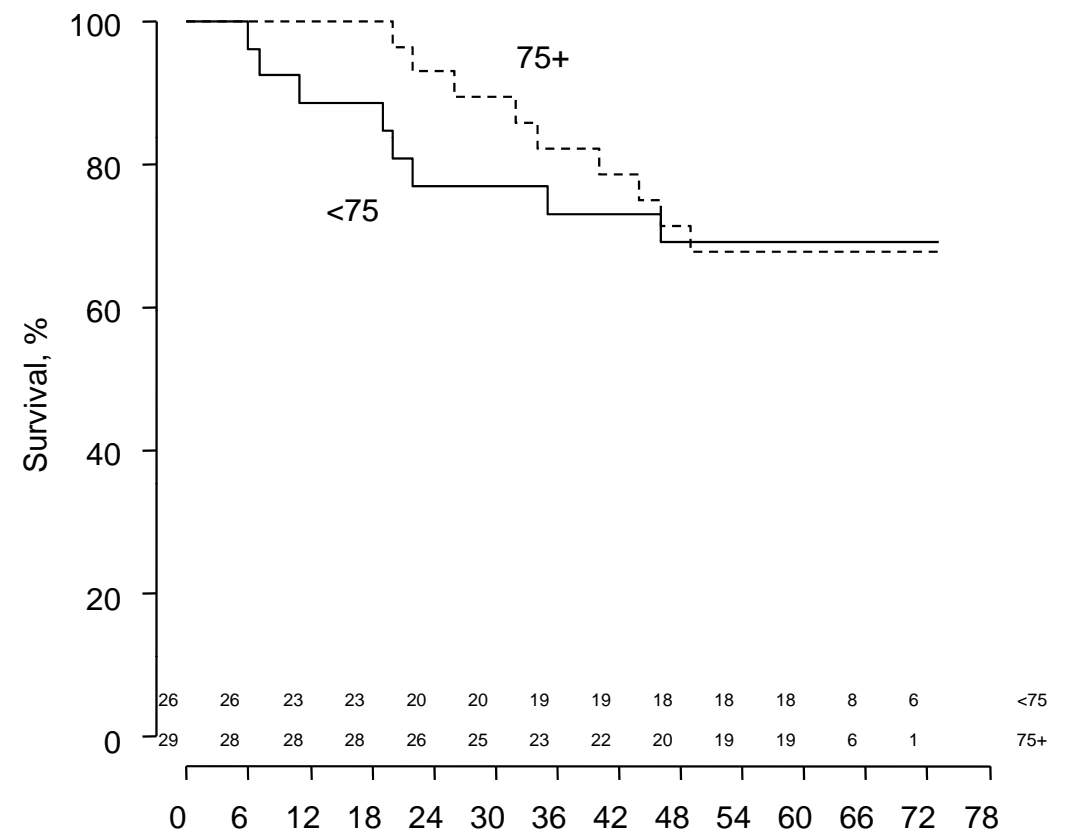

Survival, months

Fig. (1). Overall survival in two groups of patients: $\geq 75$ years old and $<75$ years old. The number of patients at risk are shown at the bottom.

of long-term results of laparoscopic colorectal cancer resection involving 3346 patients [5]. The Cochrane analysis concluded that trials also including elderly patients with comorbidity were needed, since the study population then would resemble the general population more closely. In the Barcelona study of Lacy et al. [14] the median age of the patients was 68 and 71 years in the laparoscopic and open group, respectively $(\mathrm{p}=0.02)$. Co-morbidity was not mentioned. In the COST study the median age was 70 and 69 years in the two groups, respectively, and $86 \%$ of the patients were in the ASA groups 1 or 2 . In the COLOR trial the median age was 71 years and patients in ASA groups 1 and 2 were approximately $80 \%$ in both the laparoscopic and open group. Finally, in the CLASICC trial the mean age was 69 years and the WHO performance status was in the categories 0 or 1 in nearly $90 \%$ of the patients. Thus, the patients from these studies to a certain extent seem selected excluding the elderly patients with a high co-morbidity. In the present study the median age in the elderly patients was 79 years and only $52 \%$ was in ASA groups 1 or 2 opposite to the younger group of patients which was more similar to the patients from the above mentioned randomized trials with a median age of 70 years and ASA score 1 or 2 in $73 \%$ of the patients. The overall mortality in the Danish population in the age group of 70-80 years old inhabitants is the double of the 6070 years old (16\% versus $7 \%$ ) in a five years period) [15]. Therefore, it is remarkable that the outcome with regard to overall mortality is almost similar in the two groups and comparable to the outcomes from the randomized studies, also. Thus, the overall mortality in the Barcelona study [14] was $36 \%$ compared to $34 \%$ in the elderly group in the present study, while the cancer-related mortality in the present study in the elderly was $6 \%$ against $16 \%$ in the Barcelona study. The distribution of stages and interventions was fairly identical in the two studies.

In the Barcelona study [14] a survival benefit of laparoscopic surgery was seen in patients with stage III tumors. Correspondently, in the present study no difference was found in the recurrence rate between stage II and III patients 
and the overall recurrence rate was equal to or even better than the rate in the laparoscopic group in the Barcelona study (13 versus 18\%). A possible explanation for this could be the lesser supression of the immune system in laparoscopic surgery $[16,17]$. Surgery itself is believed to increase the risk of recurrence by releasing tumor cells into circulation, decreasing antiangiogenic factors, increasing growth factors, and causing immunosuppression. These risk factors are transitory, and the fate of residual disease is probably decided within days; therefore the immediate postsurgical period appears to play a disproportional role in determining longterm recurrence [17]. In a systematic review of enhanced recovery programmes in colonic surgery it was shown that the morbidity was significantly lower than for conventional regimens [18]. It has also been shown that the presence of perioperative complications adversely affects the long-term oncologic outcome [7]. Thus, the beneficial oncologic result in the present study could be a combined effect of laparoscopic surgery and the enhanced recovery programme. In this context it should be mentioned that the median postoperative hospital stay in the present study was 5 days and not 3 days as planned, maybe due the relatively high comorbidity of the patients. A similar difference between planned and real discharge is seen in other studies, as well, but the important factor is probably that the principles for the fast-track regimen has been followed $[9,12]$.

Patients with major co-morbidities including elderly often are denied laparoscopic colorectal resections because they are thought to be at too"high risk". Nevertheless, several studies as mentioned earlier have shown a beneficial short-term effect of laparoscopic colorectal cancer surgery in elderly people [1-4]. A recent paper dealing with redefining contraindications to laparoscopic colorectal resection for high-risk patients has concluded that in experienced hands, laparoscopic colorectal surgery can be performed safely for these patients and argued against using parameters of increased age, morbid obesity, high ASA class, or preoperative radiation alone as contraindications to even complex laparoscopic colorectal procedures [19].

The present study has some limitations in the small number of partly selected patients not being randomized to its two groups, but in conclusion it seems that laparoscopic surgery and fast-track regimen together have a beneficial effect on long-term oncologic results in colorectal cancer surgery in the elderly. However, further studies of the laparoscopic approach in elderly patients with co-morbidity are needed, as well as studies of the oncologic effect of enhanced recovery programmes, which for the time being are totally lacking.

\section{ACKNOWLEDGEMENTS}

The authors thank Bent Kristensen, Head of Department of Clinical Physiology, Hillerød Hospital, Denmark, for statistical assistance with the manuscript.

\section{REFERENCES}

[1] Senagore AJ, Madbouly KM, Fazio VW, et al. Advantages of laparoscopic colectomy in older patients. Arch Surg 2003: 138: 252-6.

[2] Feng B, Zheng MH, Mao ZH, et al. Clinical advantages of laparoscopic cancer surgery in the elderly. Aging Clin Exp Res 2006; 18: 191-5.

[3] Frasson M, Braga M, Vignali A, Zuliani W, Di Carlo V. Benefits of laparoscopic colorectal resection are more pronounced in elderly patients. Dis Colon Rectum 2008; 51: 296-300.

[4] Person B, Cera SM, Sands DR, et al. Do elderly patients benefit from laparoscopic colorectal surgery? Surg Endosc 2008; 22: 4015.

[5] Kuhry E, Schwenk W, Gaupset R, Romild U, Bonjer HJ. Longterm results of laparoscopic colorectal cancer resection. Cochrane Database Syst Rev 2008; 2: CD003432. DOI: 10.1002/14651858. CD003432.pub2.

[6] Kirchoff P, Dincler S, Buchmann P. A multivariate analysis of potential risk factors for intra- and postoperative complications in 1316 elective laparoscopic colorectal procedures. Ann Surg 2008; 248: 259-65.

[7] Law WL, Choi HK, Lee YM, Ho JWC. The impact of postoperative complications on long-term outcomes following curative resection for colorectal cancer. Ann Surg Oncol 2007;14: 2559-66.

[8] Cheung HYS, Chung CC, Fung JTK, Wong JCH, Yau KKK, Li MKW. Laparoscopic resection for colorectal cancer in octogenarians: results in a decade. Dis Colon Rectum 2007; 50: 1905-10.

[9] Wind J, Polle SW, Fung Kon Jin PH, et al. on behalf of LAFA Study Group, ERAS Group. Systematic review of enhanced recovery programmes in colonic surgery. Br J Surg 2006; 93: 800-9.

[10] Bulut O,Brink L, Jess P. Laparoscopy-assisted colon resection. A prospective study with short term results and 12-38 months' follow-up. Ugeskr Laeger 2005; 167: 2882-6.

[11] Basse L, Hjort JD, Billesbolle P, Werner M, Kehlet H. A clinical pathway to accelerate recovery after colonic resection. Ann Surg 2000; 232 : 51-7.

[12] Hammer J, Harling H, Wille-Jørgensen P. Implementation of the scientific evidence into daily practice - example from fast-track colonic cancer surgery. Colorectal Dis 2008; 10:593-8.

[13] The Transatlantic Laparoscopically Assisted vs Open Colectomy Trials Study Group Laparoscopically assisted vs Open Colectomy for colon cancer. A meta-analysis. Arch Surg 2007; 142: 298-303.

[14] Lacy AM, Delgado S, Castells A, et al. The long-term results of a randomized clinical trial of laparoscopy-assisted versus open surgery for colon cancer. Ann Surg 2008; 248: 1-7.

[15] Average lifetime 2006/2007 (Middellevetid 2006/2007). Danmarks Statistik 2008. Available at http://www.dst.dk/nyt.

[16] Novitsky YW, Litwin DEM, Callery MP. The net immunologic advantage of laparoscopic surgery. Surg Endosc 2004; 18: 1411-9.

[17] Evans C, Galustian C, Kumar D, et al. Impact of surgery on immunologic function: comparison between minimally invasive techniques and conventional laparotomy for surgical resection of colorectal tumors. Am J Surg 2009; 197:238-45.

[18] Wind J, Polle SW, Fung Kon Jin PHP, et al.on behalf of the Laparoscopy and/or Fast Track Multimodal Management Versus Standard Care (LAFA) study group and the enhance Recovery After Surgery (ERAS) group. Systematic review of enhanced recovery programmes in colonic surgery. Br J Surg 2006;93: 800-9.

[19] Marks JH, Kawun UB, Hamdan W, Marks G. Redefining contraindications to laparoscopic colorectal resection for high-risk patients. Surg Endosc 2008; 22: 1899-904. 